\title{
Efek Samping Obat Antituberkulosis Kategori I dan II Pasien Tuberkolosis Paru Dewasa di Rumah Sakit Hasan Sadikin
}

\author{
Elsa P. Pratiwi ${ }^{1}$, Enny Rohmawaty ${ }^{2}$, Iceu D. Kulsum ${ }^{3}$ \\ ${ }^{1}$ Fakultas Kedokteran, Universitas Padjadjaran, Sumedang, Indonesia, \\ ${ }^{2}$ Departemen Ilmu Kedokteran Dasar, Fakultas Kedokteran, Universitas Padjadjaran, \\ Bandung, Indonesia, ${ }^{3}$ Departemen Ilmu Penyakit Dalam, Fakultas Kedokteran, Universitas \\ Padjadjaran, Bandung, Indonesia/Rumah Sakit Dr. Hasan Sadikin, Bandung, Indonesia
}

\begin{abstract}
Abstrak
Terapi tuberkulosis (TB) menggunakan beberapa antibiotik yang sering diberikan dalam Kombinasi Dosis Tetap (KDT) kategori I dan II berdasarkan Directly Observed Treatment Short-course (DOTS). Kombinasi berbagai jenis obat antituberkulosis (OAT) dan durasi terapi yang lama bisa menimbulkan efek samping. Tujuan penelitian ini adalah untuk mengetahui gambaran dan frekuensi efek samping OAT kategori I dan II. Penelitian cross-sectional ini mengambil data dari rekam medis pasien TB paru dewasa di Klinik DOTS Rumah Sakit Dr. Hasan Sadikin Bandung, Indonesia, pada periode Juli 2015Juni 2016. Data yang diambil adalah jenis TB, jenis OAT, efek samping dan waktu kemunculan efek samping. Dari 178 pasien, 27 pasien $(15,2 \%)$ mengalami efek samping. Jumlah pasien dengan OAT kategori I yang mengalami efek samping sebanyak 22 pasien, sedangkan OAT kategori II sebanyak 5 pasien. Efek samping terbanyak adalah hepatotoksisitas. Efek samping di kategori I paling banyak adalah hepatotoksisitas (52\%) sedangkan di kategori II frekuensinya sama yaitu $20 \%$ yang terdiri dari hepatotoksisitas, gangguan gastrointestinal, ruam dan gatal, gangguan neurologi dan gagal ginjal. Efek samping pada kategori I banyak terjadi di bulan pertama (48\%), sedangkan kategori II banyak terjadi di bulan pertama dan kedua yang masing-masing adalah $40 \%$. Efek samping tidak berhubungan dengan usia dan jenis kelamin (nilai $\mathrm{p}>0,05$ ). Kesimpulan penelitian ini adalah kejadian efek samping OAT kategori I dan II bervariasi dan terdapat 27 pasien yang mengalami satu atau lebih efek samping dengan efek samping terbanyak adalah hepatotoksisitas.
\end{abstract}

Kata kunci: Efek samping, obat antituberkulosis, tuberkulosis paru

\section{Adverse Reactions of Category I and II Regimens of Anti-tuberculosis Drugs among Adult Pulmonary Tuberculosis Patients in Hasan Sadikin General Hospital}

\begin{abstract}
Anti-tuberculosis therapy (ATT) with multiple antibiotics, administered as category I and II regimens fixed dose combination (FDC) which based on Directly Observed Treatment Short-course (DOTS) is commonly used. Since the process of this treatment is long-term and consists of multidrug, adverse reaction may occur. The aim of this study was to find the description and frequency of adverse reactions during the therapy of category I and II regimens of ATT. This cross-sectional study used data which was taken from adult pulmonary TB medical record at DOTS clinic of Hasan Sadikin General Hospital, Bandung, Indonesia, in the period of July 2015-June 2016. The data consisted of type of TB, drug choice, adverse effect and the time of emergence. Among 178 patients, 27 patients $(15.2 \%)$ experienced adverse effects which consisted of 22 patients in category I regimens and 5 patients in category II regimens. The majority of adverse effects is hepatotoxicity. Adverse effects occurred in category I regimens mostly was hepatotoxicity (52\%) and in category II regimens were hepatotoxicity, gastrointestinal disorder, skin reactions, neurological disorder and renal failure, with each frequency was $20 \%$. Adverse effects in category I regimens mostly occurred in first month (48\%) and in category II regimens mostly occurred in first and second month, with both frequencies were $40 \%$. Side effects were not related to age and sex ( $\mathrm{p}$-value $>0.05$ ). The conclusion of this study is there were various pattern of adverse reactions of category I and II regimens of ATT. A total of 27 patients experienced one or more adverse reactions, the most frequent reaction was hepatotoxicity.
\end{abstract}

Keywords: Adverse effects, anti-tuberculosis drugs, pulmonary tuberculosis

Korespondensi: Elsa P. Pratiwi, Fakultas Kedokteran, Universitas Padjadjaran, Bandung, Jawa Barat 45363, Indonesia, email: elsapp13@gmail.com

Naskah diterima: 12 Maret 2018, Diterima untuk diterbitkan: 3 September 2018, Diterbitkan: 1 Desember 2018 


\section{Pendahuluan}

Penyakit tuberkulosis (TB) merupakan suatu penyakit infeksi menular yang disebabkan oleh bakteri Mycobacterium tuberculosis (MTB) dan dapat menyerang beberapa organ, terutama paru. ${ }^{1}$ Laporan World Health Organization (WHO) pada tahun 2016 menyatakan bahwa pada tahun 2015 diperkirakan terdapat 10,4 juta kasus TB baru. Akumulasi kasus TB di enam negara menghasilkan $60 \%$ dari seluruh kasus TB baru di seluruh dunia. Enam negara tersebut yaitu India, Indonesia, China, Nigeria, Pakistan dan Afrika Selatan. ${ }^{2}$ Pada laporan Kementerian Kesehatan Republik Indonesia (Kemenkes RI) tahun 2015, jumlah kasus TB tertinggi berada di Jawa Barat, Jawa Timur dan Jawa Tengah. ${ }^{3}$ Rumah Sakit Dr. Hasan Sadikin di Jawa Barat merupakan rumah sakit pendidikan yang menjadi rujukan pengobatan TB.

Pengendalian TB yang menjadi rekomendasi WHO adalah penerapan strategi pengobatan jangka pendek dengan pengawasan langsung atau Directly Observed Treatment Shortcourse (DOTS). Strategi DOTS mempunyai lima buah komponen kunci, yaitu komitmen politis dengan peningkatan dan kesinambungan pendanaan; penemuan kasus dengan melalui pemeriksaan dahak mikroskopis yang terjamin mutunya; pengobatan yang standar dengan supervisi dan dukungan bagi pasien penderita; sistem pengelolaan dan ketersediaan obat anti -tuberkulosis (OAT) yang efektif; dan sistem monitoring, pencatatan dan pelaporan yang mampu memberikan penilaian terhadap hasil pengobatan pasien dan kinerja program.

Terapi OAT berlangsung dalam dua tahap, yaitu tahap intensif dan tahap lanjutan, dengan durasi total pada kategori I adalah enam bulan dan untuk kategori II adalah delapan bulan. OAT lini pertama terdiri dari isoniazid $(\mathrm{H})$, rifampisin $(\mathrm{R})$, etambutol $(\mathrm{E})$, pirazinamid $(\mathrm{Z})$, dan streptomisin (S). Kategori I terdiri dari dua bulan kombinasi dosis tetap (KDT)
HRZE dan empat bulan KDT $\mathrm{HR}+\mathrm{S}$ yang diberikan pada pasien baru. Kategori II terdiri dari dua bulan KDT HRZE+S, satu bulan KDT HRZE, dan lima bulan HR+E yang diberikan pada pasien yang pernah diobati sebelumnya. ${ }^{1}$

Berdasarkan kondisi pengobatan TB yang memiliki durasi pemberian obat yang lama serta jenis obat yang banyak, akan muncul risiko tinggi timbulnya efek samping atau toksisitas. Tujuan penelitian ini adalah untuk mengetahui jenis dan frekuensi kejadian efek samping OAT kategori I dan II pada pasien TB paru dewasa yang menjalani terapi di Klinik DOTS RSUP Dr. Hasan Sadikin pada periode Juli 2015 sampai Juni 2016. Hasil penelitian ini diharapkan dapat menjadi acuan dalam proses pengobatan TB untuk mengantisipasi munculnya efek samping TB.

\section{Metode}

Penelitian ini dilaksanakan pada bulan AprilJuni 2017 di Rumah Sakit Dr. Hasan Sadikin dengan menggunakan metode deskriptif dan pendekatan cross-sectional. Pengambilan data dilakukan secara retrospektif menggunakan data sekunder berupa rekam medis pasien TB paru dewasa. Metode pengambilan sampel adalah total sampling. Subjek penelitian ini adalah rekam medis pasien TB paru dewasa di Klinik DOTS Rumah Sakit Dr. Hasan Sadikin dari bulan Juli 2015 sampai Juni 2016 dengan kriteria inklusi yaitu pasien TB paru dewasa yang berusia $>18$ tahun dan $<60$ tahun dalam terapi OAT kategori I dan II. Kriteria eksklusi pada penelitian ini adalah rekam medis yang datanya tidak lengkap, dan data pasien yang sebelum didiagnosis TB paru sudah memiliki penyakit hati kronik, gangguan pendengaran, gangguan psikiatri, gangguan neurologi dan gagal ginjal.

Hepatotoksisitas di penelitian ini didefinisikan dengan kondisi meningkatnya alanine (ALT) atau aspartate transaminase (AST) sebesar tiga kali lipat dari upper limit of normal (ULN) 
dengan disertai gejala (sakit perut, nausea, muntah, unexplained fatigue, atau jaundice) atau meningkat lima kali lipat dari ULN tanpa disertai gejala. ${ }^{4}$ Gangguan pencernaan dikonfirmasi dengan keluhan seperti nausea, muntah, anoreksia dan diare yang dikeluhkan oleh pasien. Ruam-ruam dan gatal pada kulit merupakan tanda dan gejala dari ruam beserta gatal pada kulit yang dikeluhkan oleh pasien. ${ }^{5}$ Gangguan neurologi dikarakteristikkan dengan symmetrical polyneuropathy, gangguan pada penglihatan, psychosis dan vertigo. ${ }^{6}$ Gangguan ginjal kronik terjadi pada pasien-pasien yang mengalami oliguria, urinary cast, proteinuria, dan menurunnya creatinine clearance. ${ }^{5}$

Variabel yang diambil untuk penelitian ini adalah karakteristik pasien (jenis kelamin dan usia), status TB (jenis TB, jenis OAT), jenis efek samping serta waktu saat pertama kali efek samping tersebut muncul. Analisis data lalu dilakukan secara deskriptif dengan menghitung jumlah dan persentase serta tabulasi silang.

Pengambilan data dari rekam medis pasien dilaksanakan setelah mendapatkan izin dari Komite Etik Penelitian Kesehatan Fakultas Kedokteran Universitas Padjadjaran Bandung No. 269/UN6.C10/PN/2017 dan izin dari Komite Etik Penelitian Kesehatan RSUP Dr. Hasan Sadikin No. LB.02.01/X.2.2.1/8455/2017.

\section{Hasil}

Dari total 490 rekam medis pasien TB yang diperoleh, terdapat sebanyak 178 rekam medis yang memenuhi kriteria inklusi dan eksklusi. Pada Tabel 1, ditunjukkan bahwa pasien yang mengonsumsi OAT kategori I dan II paling banyak berjenis kelamin laki-laki. Dua puluh tujuh pasien mengalami satu atau lebih efek samping. Efek samping OAT paling banyak terjadi pada laki-laki dan pada kelompok usia 30-39 tahun.

Data pada Tabel 2 menunjukkan distribusi kemunculan efek samping lebih banyak terjadi di OAT kategori I. Efek samping lebih banyak ditemukan pada pasien laki-laki, dan pada kelompok usia paling tua di OAT kategori I. Kejadian efek samping tidak berhubungan dengan jenis kelamin dan usia (nilai $p>0,05$ ).

Berdasarkan Tabel 3, dapat dilihat bahwa lebih dari setengah pasien OAT kategori I mengalami hepatotoksisitas. Efek samping lain yang terjadi yaitu gangguan tidur dan trombositopenia. Frekuensi setiap efek samping memiliki angka yang sama pada OAT kategori II.

Tabel 4 dan 5 menunjukkan efek samping pada OAT kategori I dan II banyak terjadi di dua bulan pertama. Kejadian efek samping makin menurun seiring bertambahnya waktu pengobatan pada OAT kategori II.

Tabel 1 Karakteristik Pasien TB Paru Dewasa

\begin{tabular}{lccc}
\hline \multirow{2}{*}{ Karakteristik } & OAT Kategori I & OAT Kategori II & Efek Samping \\
\cline { 2 - 3 } & $\mathbf{n}(\%)$ & $\mathbf{n}(\mathbf{\%})$ & $\mathbf{n}(\%)$ \\
\hline Jenis Kelamin & & & $15(55,5)$ \\
Laki-laki & $77(60,2)$ & $33(66,0)$ & $12(44,5)$ \\
Perempuan & $51(39,8)$ & $17(34,0)$ & $6(22,2)$ \\
Usia & & & $10(37,0)$ \\
19-29 tahun & $49(38,3)$ & $12(24,0)$ & $3(11,1)$ \\
30-39 tahun & $41(32,0)$ & $16(32,0)$ & $8(29,7)$ \\
$40-49$ tahun & $13(10,2)$ & $15(30,0)$ & $27(15,2)$ \\
50-59 tahun & $25(19,5)$ & $7(14,0)$ & $50(28,0)$ \\
Total & $128(72,0)$ & & \\
\hline
\end{tabular}


Tabel 2 Distribusi Kemunculan Efek Samping OAT Kategori I dan II pada Pasien TB Paru Dewasa Berdasarkan Umur dan Jenis Kelamin

\begin{tabular}{|c|c|c|c|c|c|c|}
\hline \multirow{2}{*}{ Karakteristik } & \multicolumn{2}{|c|}{ Efek Samping OAT Kategori I } & \multirow{2}{*}{$\begin{array}{c}\text { Nilai } \\
\mathbf{p}\end{array}$} & \multicolumn{2}{|c|}{ Efek Samping OAT Kategori II } & \multirow{2}{*}{$\begin{array}{c}\text { Nilai } \\
\mathbf{p}\end{array}$} \\
\hline & Ada $(n,(\%))$ & Tidak Ada (n,(\%)) & & Ada $(n,(\%))$ & Tidak Ada (n,(\%)) & \\
\hline Jenis Kelamin & & & 0,911 & & & 0,200 \\
\hline Laki-laki & $13(59,1)$ & $64(60,4)$ & & $2(40,0)$ & $31(68,9)$ & \\
\hline Perempuan & $9(40,9)$ & $42(39,6)$ & & $3(60,0)$ & $14(31,1)$ & \\
\hline Usia (tahun) & & & 0,334 & & & 0,067 \\
\hline $19-29$ & $6(27,3)$ & $43(40,6)$ & & 0 & $12(26,7)$ & \\
\hline $30-39$ & $6(27,3)$ & $35(33,0)$ & & $4(80,0)$ & $12(26,7)$ & \\
\hline $40-49$ & $3(13,6)$ & $10(9,4)$ & & 0 & $15(33,3)$ & \\
\hline $50-59$ & $7(31,8)$ & $18(17,0)$ & & $1(20,0)$ & $6(13,3)$ & \\
\hline Total & $22(17,2)$ & $106(82,8)$ & & $5(10,0)$ & $45(90,0)$ & \\
\hline
\end{tabular}

\section{Pembahasan}

Dari total 178 pasien yang mengonsumsi OAT kategori I dan II, 27 pasien $(15,2 \%)$ di antaranya mengalami satu atau lebih efek samping. Hasil penelitian ini tidak berbeda jauh dengan hasil penelitian yang dilakukan di salah satu rumah sakit di Malaysia yang menyatakan bahwa $15,8 \%$ pasien mengalami efek samping OAT. ${ }^{7}$ Penelitian yang dilakukan di Nepal memiliki hasil yang berbeda yaitu $54,74 \%$ mengalami efek samping. Perbedaan hasil ini bisa dikarenakan perbedaan genetik dan demografi dengan Nepal dan data efek samping di Nepal yang lebih lengkap. ${ }^{8}$

Distribusi kemunculan efek samping lebih banyak terjadi di OAT kategori I dibandingkan kategori II. Hal ini dapat dikarenakan jumlah pasien yang mengonsumsi OAT kategori I jauh lebih banyak dibandingkan kategori II sehingga memengaruhi angka kejadian efek samping di masing-masing kategori.

Efek samping lebih banyak muncul pada pasien laki-laki $(59,1 \%)$ di OAT kategori I, sedangkan pada OAT kategori II tidak ada perbedaan yang signifikan antara laki-laki dan perempuan. Hasil penelitian oleh Alomar menyatakan bahwa perempuan lebih banyak mengalami efek samping dibandingkan lakilaki. ${ }^{9}$ Perempuan, dibandingkan laki-laki, memiliki berat badan dan ukuran organ yang lebih rendah, lebih banyak lemak di tubuh, perbedaan motilitas lambung dan laju filtrasi glomerulus yang lebih rendah. Perbedaan karakteristik ini memengaruhi farmakokinetik dan farmakodinamik suatu obat. ${ }^{9,10}$ Perbedaan

Tabel 3 Jenis Efek Samping yang Muncul pada OAT Kategori I dan II

\begin{tabular}{lcc}
\hline \multirow{2}{*}{ Jenis Efek Samping } & OAT Kategori I & OAT Kategori II \\
\cline { 2 - 3 } & $\mathbf{n}(\mathbf{\%})$ & $\mathbf{n}(\mathbf{\%})$ \\
\hline Hepatotoksisitas & $13(52)$ & $1(20)$ \\
Gangguan Pencernaan & $4(16)$ & $1(20)$ \\
Ruam/Gatal Kulit & $5(20)$ & $1(20)$ \\
Gangguan Neurologi & 0 & $1(20)$ \\
Gagal Ginjal Kronik & $1(4)$ & $1(20)$ \\
Lainnya & $2(8)$ & 0 \\
Total & $\mathbf{2 5 ( 1 0 0 )}$ & $\mathbf{5 ( 1 0 0 )}$ \\
\hline
\end{tabular}


Tabel 4 Waktu Kemunculan Efek Samping OAT Kategori I (Per Bulan)

\begin{tabular}{|c|c|c|c|c|c|c|c|}
\hline \multirow{3}{*}{ Efek Samping } & \multicolumn{6}{|c|}{ Waktu Kemunculan Efek Samping (Bulan ke-...) } & \multirow{3}{*}{$\begin{array}{l}\text { Total } \\
\text { n (\%) }\end{array}$} \\
\hline & 1 & 2 & 3 & 4 & 5 & 6 & \\
\hline & n $(\%)$ & n $(\%)$ & n (\%) & n (\%) & n (\%) & n (\%) & \\
\hline Hepatotoksisitas & $8(61,5)$ & $3(23,1)$ & $2(15,4)$ & 0 & 0 & 0 & $13(52,0)$ \\
\hline Gangguan Pencernaan & $1(25,0)$ & 0 & 0 & $1(25,0)$ & $1(25,0)$ & $1(25,0)$ & $4(16,0)$ \\
\hline Ruam/Gatal Kulit & $2(40,0)$ & $1(20,0)$ & $1(20,0)$ & 0 & 0 & $1(20,0)$ & $5(20,0)$ \\
\hline Gangguan Neurologi & 0 & 0 & 0 & 0 & 0 & 0 & 0 \\
\hline Gagal Ginjal Kronik & 0 & 0 & 0 & $1(100,0)$ & 0 & 0 & $1(4,0)$ \\
\hline Lainnya & $1(50,0)$ & 0 & 0 & 0 & 0 & $1(50,0)$ & $2(8,0)$ \\
\hline Total & $12(48,0)$ & $4(16,0)$ & $3(12,0)$ & $2(8,0)$ & $1(4,0)$ & $3(12,0)$ & $25(100,0)$ \\
\hline
\end{tabular}

hasil penelitian pada OAT kategori I dengan hasil penelitian Alomar dapat dikarenakan jumlah pasien laki-laki pada penelitian ini lebih banyak dibandingkan perempuan.

Penelitian yang dilakukan di Iran terhadap pasien yang mengonsumsi OAT lini pertama memperoleh hasil efek samping yang paling sering terjadi adalah gangguan di dalam sistem hepatobilier dengan prevalensi sebesar 35,7\%. ${ }^{11}$ Hasil penelitian tersebut hampir sama dengan hasil penelitian ini yang menunjukkan bahwa hepatotoksisitas merupakan efek samping yang paling sering terjadi pada pasien yang mengonsumsi OAT kategori I, yaitu terjadi di 13 pasien $(52 \%)$.

Efek samping pada OAT kategori I lebih banyak terjadi di kelompok usia paling tua yaitu 50-59 tahun $(31,8 \%)$ dan yang paling sering muncul yaitu hepatotoksisitas. Sejumlah penelitian sebelumnya menunjukkan adanya keterkaitan antara faktor usia dan kemunculan hepatotoksisitas. Sebuah penelitian case-control di India menyatakan bahwa hepatotoksisitas lebih sering terjadi pada pasien yang berusia lebih tua $(\mathrm{p}<0,01)$, dengan total $61 \%$ terjadi di rentang usia 35-65 tahun. ${ }^{12}$

Ramappa et al. dalam hasil penelitiannya menyebutkan bahwa usia tua berkaitan erat dengan penurunan aliran darah ke hati dan perubahan distribusi dan metabolisme obat, sehingga berpotensi mengurangi efektivitas proses eliminasi obat. ${ }^{4}$ Hal ini didukung juga oleh hasil penelitian Alomar yang menyatakan bahwa semakin meningkat/tua usia seseorang, fungsi ginjal untuk mengekskresikan obat akan semakin menurun, dan fungsi metabolisme

Tabel 5 Waktu Kemunculan Efek Samping OAT Kategori II (Per Bulan)

\begin{tabular}{|c|c|c|c|c|c|c|c|c|c|}
\hline \multirow{3}{*}{ Efek Samping } & \multicolumn{8}{|c|}{ Waktu Kemunculan Efek Samping (Bulan ke-...) } & \multirow{3}{*}{$\begin{array}{c}\text { Total } \\
\text { n }(\%)\end{array}$} \\
\hline & 1 & 2 & 3 & 4 & 5 & 6 & 7 & 8 & \\
\hline & n $(\%)$ & n $(\%)$ & n $(\%)$ & n $(\%)$ & n $(\%)$ & n $(\%)$ & n $(\%)$ & n $(\%)$ & \\
\hline Hepatotoksisitas & 0 & $1(100)$ & 0 & 0 & 0 & 0 & 0 & 0 & $1(20)$ \\
\hline Gangguan Pencernaan & $1(100)$ & 0 & 0 & 0 & 0 & 0 & 0 & 0 & $1(20)$ \\
\hline Ruam/Gatal Kulit & $1(100)$ & 0 & 0 & 0 & 0 & 0 & 0 & 0 & $1(20)$ \\
\hline Gangguan Neurologi & 0 & $1(100)$ & 0 & 0 & 0 & 0 & 0 & 0 & $1(20)$ \\
\hline Gagal Ginjal Kronik & 0 & 0 & 0 & $1(100)$ & 0 & 0 & 0 & 0 & $1(20)$ \\
\hline Lainnya & 0 & 0 & 0 & 0 & 0 & 0 & 0 & 0 & 0 \\
\hline Total & $2(40)$ & $2(40)$ & $\mathbf{0}$ & $1(20)$ & $\mathbf{0}$ & 0 & $\mathbf{0}$ & $\mathbf{0}$ & $5(100)$ \\
\hline
\end{tabular}


obat di hati pun akan semakin menurun. ${ }^{9}$ Hasil penelitian pada OAT kategori I sesuai dengan hasil kedua penelitian tersebut, namun hasil pada OAT kategori II berbeda. Efek samping pada OAT kategori II banyak terjadi pada kelompok usia 30-39 tahun karena jumlah pasiennya paling banyak dan paling sedikit pada kelompok usia 50-59 tahun.

Penelitian ini menunjukkan pada kategori I maupun kategori II memiliki nilai $\mathrm{p}>0.05$ yang menunjukkan bahwa tidak ada hubungan signifikan antara efek samping OAT dengan jenis kelamin dan usia. Sementara itu, hasil penelitian pada OAT kategori I menunjukkan hampir setengah (48\%) dari total efek samping terjadi di bulan pertama dan $16 \%$ terjadi di bulan kedua, dengan efek samping terbanyak yaitu hepatotoksisitas. Efek samping dari OAT kategori II banyak dialami pasien di bulan pertama (40\%) dan bulan kedua (40\%). Hal ini sesuai dengan hasil penelitian di Malaysia yang menunjukkan adanya keterkaitan antara kejadian efek samping dan kemunculan efek samping di fase intensif. ${ }^{7}$

Isoniazid, rifampisin dan pirazinamid adalah jenis OAT yang dapat menyebabkan hepatotoksisitas. Ketiga obat tersebut akan dilakukan metabolisme di dalam hati, sehingga proses tersebut diyakini sebagai akibat dari timbulnya hepatotoksisitas..$^{4,7,12-14}$ Kombinasi dari ketiga obat tersebut diberikan selama fase intensif yaitu dua bulan pertama pada OAT kategori I dan tiga bulan pertama pada OAT kategori II. ${ }^{1}$ Kombinasi tiga obat tersebut akan menyebabkan peningkatan risiko terjadinya hepatotoksisitas pada fase intensif. ${ }^{12}$ Hasil suatu penelitian di China, $71.59 \%$ pasien TB mengalami hepatotoksisitas pada dua bulan pertama. ${ }^{15}$ Fakta-fakta tersebut sesuai dengan hasil penelitian ini, yaitu hepatotoksisitas pada OAT kategori I terjadi paling banyak di bulan pertama dan kedua, sedangkan pada OAT kategori II terjadi di bulan kedua.

Jenis efek samping pada OAT kategori I lainnya selain hepatotoksisitas adalah ruam/ gatal kulit (20\%), gangguan pencernaan (16\%), gagal ginjal (4\%), trombositopenia (4\%) dan gangguan tidur (4\%). Efek samping akibat OAT kategori II adalah hepatotoksisitas, gangguan pencernaan, ruam/gatal pada kulit, gangguan neurologi dan gagal ginjal yang masing-masing adalah 20\%. Mayoritas efek samping yang muncul pada penelitian di Nepal berkaitan dengan sistem persyarafan pusat $(61,33 \%)$, diikuti oleh sistem muskuloskeletal (53,33\%), sistem pencernaan $(45,33 \%)$, kulit $(33,33 \%)$, sistem pernafasan (4\%), sistem endokrin (4\%), sistem vestibular (4\%), sistem okular $(2,66 \%)$ dan sistem kardiovaskular (1,33\%). ${ }^{8}$ Penelitian yang dilakukan di salah satu Puskesmas di Cimahi menyatakan bahwa hasil efek samping yang paling banyak terjadi adalah gangguan pencernaan dan keluhan tidak nafsu makan. ${ }^{16}$ Perbedaan hasil tersebut dapat disebabkan oleh perbedaan lokasi penelitian, karakteristik subjek penelitian dan proses pencatatan efek samping.

Kejadian efek samping pada penelitian ini memiliki angka yang cukup rendah, hal ini mungkin karena pasien yang mengalami efek samping memang sedikit atau tidak tercatat di rekam medis. Penggunaan data rekam medis pasien merupakan kekurangan penelitian ini, karena data efek sampingnya tidak lengkap. Kondisi pasien TB paru yang mengonsumsi OAT seharusnya selalu dipantau dan dikontrol untuk mencegah munculnya efek samping atau terjadinya efek samping yang semakin parah. Sebuah penelitian menunjukkan bahwa munculnya efek samping akan memengaruhi kepatuhan pasien untuk meminum obat dan tinggi risiko untuk menghentikan konsumsi obat tersebut. ${ }^{17}$ OAT kategori I dan kategori II harus dikonsumsi sampai habis tanpa terkecuali untuk mencegah terjadinya resisten terhadap OAT. ${ }^{18}$

Keterbatasan pada penelitian ini yaitu tidak dilakukannya analisis mengenai confounding factors, seperti adanya penyakit komorbid serta penggunaan obat lain yang bersamaan 
dengan penggunaan OAT. Untuk penelitian selanjutnya, disarankan melakukan analisis lebih lanjut mengenai berbagai macam faktor yang dapat berpengaruh pada efek samping, analisis mengenai confounding factors, dan pengambilan data dilakukan secara prospektif agar diperoleh data yang lebih lengkap.

\section{Simpulan}

Sebanyak 27 pasien $(15,2 \%)$ yang mengonsumsi OAT kategori I dan II mengalami satu atau lebih efek samping, dengan efek samping terbanyak yaitu hepatotoksisitas. Efek samping pada OAT kategori I dan II banyak terjadi di fase intensif.

\section{Ucapan Terima Kasih}

Terima kasih kepada Program Studi Sarjana Kedokteran Fakultas Kedokteran Universitas Padjadjaran yang telah menaungi penelitian ini.

\section{Pendanaan}

Penelitian ini tidak menggunakan dana hibah atau dana bantuan dari sumber manapun.

\section{Konflik Kepentingan}

Seluruh penulis menyatakan tidak terdapat potensi konflik kepentingan dengan penelitian, kepenulisan (authorship), dan/atau publikasi artikel ini.

\section{Daftar Pustaka}

1. Direktorat Jendral Pengendalian Penyakit dan Penyehatan Lingkungan. Pedoman nasional pengendalian tuberkulosis. Katalog dalam Terbitan: Kementerian Kesehatan Nasional. Jakarta: Kementerian Kesehatan Republik Indonesia; 2014.

2. World Health Organization. Global tuberculosis report 2016. World Health Organization; 2016.

3. Kementerian Kesehatan Republik Indonesia. Profil kesehatan Indonesia tahun 2015. Jakarta: Kementerian Kesehatan Republik Indonesia; 2016.

4. Ramappa V, Aithal GP. Hepatotoxicity related to anti-tuberculosis drugs: Mechanisms and management. J Clin Exp Hepatol. 2013;3(1):37-49. doi: 10.1 016/j .jceh.2012.12.001.

5. Arbex MA, Varella MDe C, Siqueira HR, Mello FA. Antituberculosis drugs: Drug interactions, adverse effects, and use in special situations. Part 2: second-line drugs. J Bras Pneumol. 2010;36(5):641-56. doi: 10.1590/S1806-37132010000500017

6. Curry International Tuberculosis Center. Drug-resistant tuberculosis: A survival guide for clinicians, 2nd edition. Curry Int Tuberc Cent Calif Dep Public Heal. 2011;145-70.

7. Kurniawati F, Azhar S, Sulaiman S, Gillani SW. Adverse drug reactions of primary anti-tuberculosis drugs among tuberculosis patients treated in chest clinic. Int J Pharm Life Sci. 2012;3(1):1331-8.

8. Chhetri AK, Saha A, Verma SC, Palaian S, Mishra P, Shankar PR. A study of adverse drug reactions caused by first line anti-tubercular drugs used in directly observed treatment, short course (DOTS) therapy in Western Nepal, Pokhara. J Pak Med Assoc. 2008;58(10):531-6.

9. Alomar MJ. Factors affecting the development of adverse drug reactions (review article). Saudi Pharm J. 2014; 22 (2):83-94. doi: 10.1016/j.jsps.2013.02.003

10. Franconi F, Brunelleschi S, Steardo L, Cuomo V. Gender differences in drug responses. Pharmacol Res. 2007;55(2):81 -95. doi: 10.1016/j.phrs.2006.11.001

11. Farazi A, Sofian M, Jabbariasl M, Keshavarz S. Adverse reactions to antituberculosis drugs in Iranian tuberculosis patients. 
Tuberc Res Treat. 2014;412893:1-6. doi: 10.11 55/2014/412893

12. Singla R, Sharma SK, Mohan A, Makharia G, Sreenivas V, Jha B, et al. Evaluation of risk factors for antituberculosis treatment induced hepatotoxicity. Indian J Med Res. 2010;132(7):81-6.

13. Tostmann A, Boeree MJ, Aarnoutse $\mathrm{RE}$, de Lange WC, van der ven AJ, Dekhuijzen R. Antituberculosis druginduced hepatotoxicity: Concise up-todate review. J Gastroenterol Hepatol. 2008; 23(2):192-202. doi: 10.1111/j.1440-1746 .2007.05207.x

14. Chang KC, Leung CC, Yew WW, Lau TY, Tam CM. Hepatotoxicity of pyrazinamide: Cohort and case-control analyses. Am J Respir Crit Care Med. 2008; 177(12):1391-6. doi: 10.1164/rccm.2008 02-355OC.
15. Shang P, Xia Y, Liu F, Wang X, Yuan Y, $\mathrm{Hu} \mathrm{D}$, et al. Incidence, clinical features and impact on anti-tuberculosis treatment of anti-tuberculosis drug induced liver injury (ATLI) in China. PLoS One. 2011; 6(7):1-7. doi: 10.1371/journal.pone.0021 836.

16. Wiyati T, Irawati D, Budiyono I. Studi efek samping obat dan penanganannya pada pasien TB paru di Puskesmas Melong Asih, Cimahi. JSTFI Indones J Pharm Sci Technol. 2014;3(1):23-30.

17. Lin J, Sklar GE, Oh VM Sen, Li SC. Factors affecting therapeutic compliance: A review from the patient's perspective. Ther Clin Risk Manag. 2008;4(1):269-86. doi: 10.2147/TCRM.S1458

18. Nugrahaeni DK, Malik US. Analisis penyebab resistensi obat anti tuberkulosis. J Kesehat Masy. 2013;8(2):113-20. 